Revista de Economia Política, vol. 32, no 2 (127), pp. 229-240, abril-junho/2012

\title{
A proteção social entre a luz e a sombra
}

\section{STEFANIA VACCARO*}

The social protection between the light and the shadow. This article tries to reveal some subject formation traces facing itself and the society that it is inserted to discuss the Social Protection importance in Knowledge Economy as the Human potentialities expansion factor. The assumption is the connection between the individual and the world happens in a dynamic relation where the individual shapes the society and the society is shaped by the individual. So Fromm's Social Psychology (1941) is used to clarify the appearing of the fears and humans passions and Gorz's No material concept (2003).

Keywords: subject; social protection; no material; knowledge economy.

JEL Classification: E20; E61; P41.

"O difícil não é aceitar ideias novas, mas escapar das velhas"

(John Maynard Keynes)

"Do lado de fora é onde deve estar nosso lado de dentro"

(Viviane Mosé)

\section{INTRODUÇÃO}

Para pensar o mundo é preciso pensar o homem em sua inteireza, pois a razão, seus medos e suas paixões moldam sua personalidade e, também, constroem suas ações sobre o mundo. As análises, contudo, costumam se ater à segurança da razão que, frequentemente, dilui a presença da subjetividade.

Um exame, no entanto, mais acurado sobre o explícito movimento do homem

\footnotetext{
* Doutoranda em Ciências Jurídicas e Sociais da Universidade Federal Fluminense. E-mail: fanivaccaro@ yahoo.com.br. Submetido: 10/Janeiro/2011; Aprovado: 28/Março/2011.
} 
em sociedade é capaz de nos revelar não só os elementos da razão, mas também, o implícito de seu ser. Ao deixarmos, todavia, de percebê-lo e questioná-lo, sua beleza - pelas possibilidades do devir - se esvai na mecanização de um roteiro previamente definido. Deste modo, é que repensar a subjetividade pode nos permitir compreender as misérias do presente e a riqueza do possivel ${ }^{1}$.

Nesse sentido é que se apresenta a importância de se discutir a (des)proteção social como um estímulo externo que modifica o ser, suas angústias, seus desejos e suas paixões e que influi diretamente no processo social ao dirigir a força produtiva do homem em certa direção.

\section{A CONDIÇÃO HUMANA}

O desenvolvimento do capitalismo permitiu ao homem acelerar o processo de individualização ${ }^{2}$, pelo que foi possível conceber a autonomia do sujeito, o seu querer, num processo de exclusão do indivíduo do todo. Deu-se, no entanto, uma primazia acrítica $^{3}$ ao desenvolvimento do "sujeito-eu", que esvaziou em grande medida o seu conteúdo ao obscurecer a outra ponta contrária à relação: a de que também somos parte inextricável do todo.

Enredados nas teias invisíveis e ambivalentes da formação do sujeito - que produziram e produzem, na subjetividade humana, muitos conflitos entre o "nós" e o "eu" (Morin, 1996) — os homens perderam, ainda mais, a clareza sobre a dinâmica do processo social que os esculpe, assim como à sociedade. É preciso, pois, ampliar o horizonte para percebermos que o "eu" independente está atravessado pelo "outro".

Assim, pensar o indivíduo em detrimento da sociedade é algo tão míope quanto o fazer inversamente. Os homens nada mais são do que as possibilidades de ser; não há neles uma natureza humana fixa e biologicamente ${ }^{4}$ dada. Como sujeitos em construção devem ser compreendidos dentro do processo histórico-social em que há uma relação indissociável ${ }^{5}$ entre os indivíduos e a sociedade, pois

\footnotetext{
${ }^{1}$ A expressão dá nome à obra de Gorz (1997) em que ele discute a configuração da fase contemporânea do capitalismo, os últimos avatares do trabalho e as possibilidades da sociedade que se prefigura.

${ }^{2}$ Fromm (1961) ressalta que na Idade Média o processo de individualização não era possível dado que o homem estava submetido às forças da natureza e não tinha consciência de si como entidade autônoma.

${ }^{3}$ Elias (1994) pontua que o embuste da visão acrítica é resultante dos termos em que se pautam rotineiramente os debates sociais, que apresentam o indivíduo como uma antítese da sociedade, quando só podem ser compreendidos pela unicidade do "nós-eu".

${ }^{4} \mathrm{O}$ fato de desconsiderar uma interpretação biologista do sujeito não afasta, contudo, as descobertas de Freud sobre a atividade inconsciente e o significado das neuroses como fatores que influenciam na formação do homem. O que se entende é que as inclinações humanas respondem a determinados estímulos externos não numa relação mecânica, mas altamente maleável em que o indivíduo é capaz de adaptar-se aos estímulos naturais e culturais e por eles modificar a si mesmo como sujeito do processo social (Fromm, 1961).

${ }^{5}$ Morin (1996) apresenta esta complementaridade tanto no processo biológico — são os seres humanos
} 
[...] La sociedad no ejerce solamente una función de represión aunque que no deja de tenerla - sino que posee también una función creadora. La naturaleza del hombre, sus pasiones y angustias son un producto cultural; en realidad el hombre mismo es la creación más importante y la mayor hazaña de ese incesante esfuerzo humano cuyo registro llamamos historia. (Fromm, 1941, p. 37)

Essa natureza, dos múltiplos horizontes possíveis do humano, não afasta, todavia, dois outros traços que também lhe são constitutivos: a exigência de autoconservaçã $\mathrm{o}^{6}$ e a necessidade de relacionar-se ${ }^{7}$ com o mundo exterior evitando o isolamento. Características essas que, em seu todo, irão inevitavelmente marcar a forma do homem agir sobre o mundo, mas não só! Há ainda um paradoxo essencial à compreensão desse agir.

Se, por um lado, o processo de individualização permitiu ao homem, em grande medida, ser ator e autor de sua história — mesmo que por muitas vezes inconscientemente - , por outro lado também evidenciou sua lástima existencial ao mostrar com clareza a finitude de seu ser e de sua insignificância diante do universo. Tão trágica percepção fez o homem vagar em busca de certezas; e a modernidade foi pródiga em atribuir modelos preconcebidos - de patamares elevadíssimos sobre o próprio conceito de vida e de felicidade ${ }^{8}$.

As interações ocasionaram um ritmo frenético à vida e o homem, em passos trôpegos, foi perdendo a compreensão sobre si mesmo. O tempo passou a ser o do destempo, em que a imperatividade do fazer ${ }^{9}$ dificulta a experiência ${ }^{10}$, o gozo do momento, do encontro com o outro e consigo. O homem, atrás da ilusão de um

produtos da reprodução sexuada e dela produtores — quanto no processo cultural, em que as interações entre os indivíduos criam signos e significantes que retroatuam sobre os indivíduos desde que esses vêm ao mundo.

${ }^{6}$ Tratam-se das necessidades fisiológicas do homem — como a fome, a sede, o sonho —, as quais não podem ter a ausência suportada. Justamente por isso Fromm (1961) as denomina de vínculo primário.

${ }^{7}$ Fromm (1961) informa que esta necessidade não está relacionada com o contato físico e sim com os sentimentos de pertencimento e de comunicação, os quais podem surgir de ideias, valores ou normas sociais.

${ }^{8}$ Freud assevera que "o que chamamos de felicidade no sentido mais restrito provém da satisfação (de preferência, repentina) de necessidades represadas em alto grau, sendo, por sua natureza, possível apenas como uma manifestação episódica. Quando qualquer situação desejada pelo princípio do prazer se prolonga, ela produz tão somente um sentimento de contentamento muito tênue. Somos feitos de modo a só podermos derivar prazer intenso de um contraste, e muito pouco de um determinado estado de coisas" (1997, p. 24).

\footnotetext{
${ }^{9}$ Nas sociedades hipnotizadas pelo alto consumo o tempo de ócio - que não significa um não fazer, mas um fazer de tantas outras coisas diferentes da rotina que nos assola - é também mercadoria. As possibilidades parecem iniciar e terminar em propostas comerciais diminuindo o eco de inúmeros outros prazeres que não requerem contratar nada, especialmente, o encontro consigo.

${ }^{10} \mathrm{O}$ termo aqui foi empregado no aspecto da importância da percepção sensorial ligada ao corpo como elemento tradutor das narrativas vividas.
} 
ideal de felicidade como destino a ser conquistado, passou a agir incessantemente sem captar, no entanto, os movimentos e as possibilidades do devir.

A vida, então, deixou de ser concebida como um percurso de risco que inclui altos e baixos, incertezas, acertos, dúvidas, sorte, acaso para ser vista como um empreendimento cujos resultados devem ser garantidos desde os primeiros anos.

Já na infância são os indivíduos impelidos a desenvolver um elevado, mas também ambíguo, grau de autocontrole ${ }^{11}$, que, se por um lado é capaz de nos permitir traçar metas a serem perseguidas e avançar no processo civilizacional (Elias, 1990), por outro lado nos submete às normas e valores sociais, muitas vezes mutilantes do "sujeito-eu".

Captar essa ambiguidade tensa nos exige um grau de distanciamento, inclusive de nós mesmos. Ocorre que quase sempre as pessoas são incapazes de olhar para o invisível do seu ser e irão se guiar - sem perceberem - pelo olhar externo. Despojados de seu "eu", costumeiramente irão empregar em seu julgamento falsos padrões de avaliação (poder, sucesso, riqueza) (Freud, 1930). Isso porque numa sociedade mediatizada pela abundância de imagens o poder, o sucesso e a riqueza são reificados ${ }^{12}$ numa ordem simbólica que captura ${ }^{13}$ a estrutura social.

Ao se afastar a dimensão conceitual desses termos, passível de ressignificações constantes, para apresentá-la como se fosse a própria coisa, dá-se a aceitação possível pelo monopólio da aparência (Debord, 1967) e, consequentemente, se estabelece "o" caminho a ser trilhado. O problema é que

Não existe uma regra de ouro que se aplique a todos: todo homem tem de descobrir por si mesmo de que modo específico ele pode ser salvo. Todos os tipos de diferentes fatores operarão a fim de dirigir sua escolha. É uma questão de quanta satisfação real ele pode esperar obter do mundo externo, de até onde é levado para tornar-se independente dele, e, finalmente, de quanta força sente à sua disposição para alterar o mundo, a fim de adaptá-lo a seus desejos. (Freud, 1930, p. 33)

O essencial aqui é descobrir que a liberdade para ser subtende conviver com dúvidas e erros; no entanto, esses são, por vezes, atemorizantes, dado o sentido de perda espraiado na sociedade atual (Fromm, 1941), que nos faz esquecer que as rupturas nunca começam do zero.

\footnotetext{
${ }^{11}$ Neste quesito, parece que o processo de aceleração do tempo hoje em curso tem levado a uma mudança substancial na capacidade de autocontrole dos indivíduos e de formação de suas subjetividades, que coladas ao corpo passam a ser descritas de forma física e imediata dentro de uma cultura das sensações. O problema aqui passa a ser, então, o da incapacidade de vivências ad hoc sustentar projetos de médio e longo prazo e, também, da sua insuficiência na construção da rapsódia da vida.

${ }^{12} \mathrm{O}$ termo foi aqui empregado no sentido filosófico de tornar-se res, transformar-se em coisa.

${ }^{13}$ Fromm (1961) alerta que ao esmaecer as diferenças entre o eu e o mundo desaparece o medo consciente da solidão e da impotência, mas numa crença ilusória de que aqueles pensamentos hegemônicos são os seus, o que ocasiona, na prática, dificuldades para romper com o estado das coisas.
} 
É preciso, então, reordenar esse sentido de perda, partindo de um olhar concreto sobre as próprias dores sem, porém, se tornar cativo delas. Eis que a dor que dilacera é também aquela que possibilita a pluralidade do devir. Seu enfrentamento traz luz às contradições e a consciência dos limites, o que possibilita a constante reinvenção de si num ato de liberdade que, todavia, não é absoluto, já que tornar-se sujeito de si significa - dentro da dupla dimensão ${ }^{14}$ da liberdade - eleger um querer individual interdependente ${ }^{15} \mathrm{com}$ a sociedade.

Compreender a solidão de nossa existência e a responsabilidade de nossa ação individual é, portanto, o segundo passo rumo ao processo de individualização ${ }^{16}$ a partir de quando há a liberdade para tornar-se. Mas, contraditoriamente, este passo que nos faz mais livres e plenos é também um passo que nos faz mais débeis, pelos sentimentos de angústia e de impotência que brotam em nosso ser.

Equilibristas de uma relação incerta acostumamos a nos abandonar e a nos submeter ao mundo exterior num processo de enfraquecimento do "sujeito-eu" que traz consigo uma dor pungente que transforma o sofrimento contingente em consubstancial ${ }^{17}$. Será, então, possível nos reencantar?

Fromm (1941) aponta que trabalho criador $^{18}$, por ser inseparável das emoções, do viver e do pensar, é capaz de permitir a ponte entre o "sujeito-eu" e o "sujeito-nós" integrando o homem ao mundo. Não se trata, porém, de um percurso fácil. O crescimento da individualização depende inegavelmente das condições individuais e, também, tem seus limites fixados pelas condicionantes socioeconômicas, que fornecem as bases para o desenvolvimento individual, sobretudo por ter o homem que se ater à imperiosa necessidade de autoconservação (Fromm, 1941).

Entender essa dinâmica significa ingressar no estudo do processo civilizacional humano e na riqueza de suas possibilidades, potencializadas para ser mais ou desconstruídas na conformação de um ser menos.

\footnotetext{
${ }^{14}$ A liberdade pressupõe uma condição interna — pela capacidade cerebral, mental, intelectual necessária para considerar as situações e realizar suas apostas - e condições externas, que trazem as constrições e contingências que influenciam nas escolhas possíveis (Morin, 1996).

${ }^{15}$ Morin (1996) identifica dependências energéticas, informativas e organizativas do mundo exterior. A energia é exigida na construção e na reconstrução da autonomia do sujeito dentro da auto-organização, sendo as dependências informativas e organizativas resultantes da extração de informações do exterior a fim de organizar os comportamentos individuais.

${ }^{16}$ Fromm (1961) aponta que o segundo degrau da individualização (o primeiro se deu pela liberação dos vínculos primários) se dá pelo processo de crescimento da força e da integração da personalidade individual. Isso significa liberar-se dos outros, pela perda da originária identidade com os outros, e de si mesmo, ao compreender seus próprios fantasmas.

${ }^{17}$ A Organização Mundial de Saúde (OMS) aponta que a depressão será a segunda doença mais grave a ocasionar a incapacidade para o trabalho em 2020 (Depressão..., 2009).

${ }^{18}$ Para evitar equivocidade no sentido atribuído à palavra trabalho autônomo, Gorz (2003) utiliza da expressão atividades no desenvolvimento prazeroso de processos criativos.
} 


\section{TENSÕES DIALÉTICAS NO PROCESSO CIVILIZACIONAL}

O processo civilizacional deve ser entendido como um todo dinâmico que não comporta, na sua substância, a transposição, para o concreto vivido, de modelos ideais ${ }^{19}$ de definição da sociedade que geram deformações no conteúdo do conhecimento. Dá-se, entretanto, que a visão humana tende a se concentrar no plano do comum $^{20}$, na superfície da realidade, mesmo que nada exista apenas sob essa forma.

Foi deste modo que, nas últimas décadas, produziu-se um intenso debate sobre o Estado neutro ou Estado como instrumento de classe; sobre o Estado mínimo ou o Estado regulador que, fechados em seus respectivos universos - construídos por suas miopias ${ }^{21}$ - pouco permitiram avançar na forma de compreensão e, consequentemente, de organização social. É, porém, preciso ter claro que “[...] Os Estados, mais do que qualquer outra forma social, emergiram no mundo inteiro como as unidades de sobrevivência de nível mais elevado" (Elias, 1990, p. 168) e hoje encontram dificuldades para desempenhar seu papel de estrutura de integração. Assim, soluções isoladas neste quadro não nos parecem factíveis de produzir resultados, já que vivemos em uma sociedade de crescente complexidade.

Neste sentido é que a compreensão da emergência do Estado de Bem-Estar Socia ${ }^{22}$ deve se dar dentro do movimento de "[...] expansão da concorrência cada vez mais imperfeita (processo de monopolização dos capitais), que tendeu a diminuir, ainda mais, a capacidade de autorregulação do mercado a partir de suas próprias forças" (Pochmann, 2004, p. 1). Deve, ainda, ser entendido como a forma capaz de congregar valores, inicialmente contraditórios - cidadania, subjetividade, direitos individuais e justiça social —, estabelecendo as condições de reprodução do capital, ao permitir meios para sua acumulação e sua legitimidade, pois

Esta forma de autoridad remite a tres funciones fundamentales: la extracción de recursos de la comunidad, la distribución y asignación de recursos e a la comunidad y la regulación de las acciones aceptables y no

\footnotetext{
${ }^{19}$ Elias (1994) pontua que um importante passo à emancipação das ciências sociais pode se dar pela maneira de colocar os problemas não mais da forma específica das ciências naturais (com base em leis clássicas de regularidades observáveis em todos os lugares e épocas) para colocá-los numa abordagem sociológico-processual.

${ }^{20}$ A visão distorcida e parcelar é fruto de inúmeros processos, especialmente, das formas fantasiadas e fetichizadas, que dificultam a compreensão da realidade e dos jogos de poder que a sustenta (Kosik, 1986), assim como, da concepção especializada que fragmenta o conhecimento (Morin, 1982).

${ }^{21}$ Carlos Drummond de Andrade, num belíssimo poema intitulado Verdade, traduz a nossa miopia sobre a realidade, em que cada um se fecha na metade da verdade, eleita conforme seus caprichos e ilusões. A arbitrariedade na eleição da verdade pode, no entanto, ser minimizada por um pensamento complexo que conduza ao diálogo.

${ }^{22}$ A análise aqui desenvolvida não ignora que “[...] o Estado de Bem-Estar Social foi uma excepcionalidade das economias que constituem o centro do capitalismo mundial, ou seja, de uma minoria de nações e também de uma parcela relativamente pequena do conjunto da população mundial” (Pochmann, 2004, p. 1)
} 
aceptables, así como la generación de incentivos y desincentivos en las otras tres esferas descentralizadas de acción: el mercado, las familias y la comunidad, (Filgueira, 2007, p. 11)

O Estado Social ${ }^{23}$ foi (é), sem dúvida, a forma política que melhor possibilitou o avanço do processo civilizacional ao permitir que os indivíduos rompessem os grilhões dos vínculos primários que os submetiam. Contudo, suas bases estiveram fincadas em certas condições materiais e sociais, que correspondiam a uma forma de produção do capitalismo industrial e de gestão no quadro do Estado-nação (Castel, 2005). Cenário esse que sofreu profundas alterações.

A partir dos anos 1980 as condicionantes estruturais da proteção social deram sinais do processo de corrosão a que estavam submetidas em um ambiente econômico "[...] marcado pela profunda desregulação da concorrência intercapitalista e por modificações importantes na base tecnológica, em meio ao predomínio das altas finanças [...]" (Pochmann, 2004, p. 5). Além disso, o crescimento da monoparentalidade, as uniões livres, a inserção crescente das mulheres no mercado laboral, o incremento do divórcio, dentre outras mudanças, transformam a distribuição, o tipo e a quantidade de risco social e, por conseguinte, a suas formas de proteção (Filgueiras, 2007).

Ainda dentro dessa nova dinâmica, a revolução informacional ${ }^{24}$ em curso "[...] permitiu gigantescas economias de tempo de trabalho na produção material, na gestão, nas comunicações, no comércio atacadista, no conjunto das atividades de escritório" (Gorz, 2005, p. 12) e permitiu que, cada vez mais, se exija menos trabalho para a produção do material trazendo dificuldades na valorização $0^{25}$ do capital, pois

Todo o conhecimento passível de formalização pode ser abstraído de seu suporte material e humano, multiplicado quase sem custos na forma de software e utilizado ilimitadamente em máquinas que seguem um padrão universal. Quanto mais se propaga, mais útil ele é à sociedade. Seu valor mercantil, ao contrário, diminui com sua propagação e tende a zero [...] (Gorz, 2003, p. 10).

\footnotetext{
${ }^{23}$ Conforme muito bem marcado por Hassenteufel (1996) o chamado Estado Social se materializou ao redor do mundo de diversas formas e atendendo a diferentes objetivos sociopolíticos, de modo que a utilização deste termo é sempre problemática; no entanto, pela sua repercussão no campo sociológico opta-se por utilizá-la neste trabalho. Para aprofundamento consultar a obra em referência.

${ }^{24}$ A doutrina é uníssona sobre as mudanças provocadas pelos processos tecnológicos, especialmente, no mundo do trabalho. Todavia, uma parte reputa impróprio o designativo $3^{a}$ revolução industrial por entender que não teria o processo produtivo sofrido modificações em todos os setores.

${ }^{25}$ Mandel (1978) explica que com o aumento da composição orgânica do capital prevalece, dentro da lei do valor, a queda tendencial da taxa de lucro, a qual só poderia ser contrabalanceada pelo aumento da taxa da mais-valia na mesma proporção. Essa, todavia, só é produzida pelo capital variável, não sendo possível reduzir a zero o tempo de trabalho necessário, o que gera um desequilíbrio na equação dos capitais.
} 
Em busca de saídas — para a dificuldade de valorização do capital — várias metamorfoses foram se processando. Deu-se um deslocamento crescente de massas de capitais para a esfera financeira, assim como, tentativas de rompimento com as regulações coletivas (que passaram a ser entendidas como pesos insuportáveis num mercado global de alta competitividade) e flexibilizações ${ }^{26}$ nos sistemas de contratação de trabalho.

No processo de criação de riqueza "[...] as empresas transformam os produtos materiais em vetores de conteúdos imateriais, simbólicos, afetivos, estéticos" (Gorz, 2005 , p. 19) e transformaram o conhecimento ${ }^{27}$ na principal ${ }^{28}$ força produtiva do sistema capitalista. De modo que

O capitalismo moderno, centrado sobre a valorização de grandes massas de capital fixo material, é cada vez mais rapidamente substituído por um capitalismo pós-moderno centrado na valorização de um capital dito imaterial, qualificado também de "capital humano", "capital conhecimento" ou "capital inteligência" (Gorz, 2005, p. 15)

Nesse contexto, o modo de produção sofreu transformações tão intensas que o desenvolvimento das forças produtivas e as relações sociais de produção passaram a se apresentar como processos supérfluos ${ }^{29}$ na dinâmica geral de reprodução do capital.

Assim, o deslocamento do processo de valorização do capital para o imaterial ${ }^{30}$ produziu mais um paradoxo na produção: por um lado estabeleceu o entrelaçamento indissociável entre cultura, artes e ciências fazendo com que esses aspectos assumam uma preponderância no processo produtivo; por outro lado transformou a maior parte dos trabalhadores (excetuando uma pequena parcela altissimamente qualificada objetiva ${ }^{31}$ e subjetivamente na trajetória de suas vidas) em descartáveis

${ }^{26} \mathrm{O}$ termo foi aqui empregado no sentido da mera desregulamentação dos direitos trabalhistas dentro do viés de recontratualização civil.

${ }^{27} \mathrm{O}$ capitalismo sempre utilizou o conhecimento na valorização do capital, mas o fazia por intermédio de sua objetivação em máquinas, instalações e processos. Hoje, todavia, está dentro de uma nova fronteira já que visa à apropriação dos conhecimentos não passíveis de formalização, tais como: a experiência, o discernimento, a capacidade de coordenação, de auto-organização e a comunicação (Gorz, 2003).

${ }^{28}$ Esta crescente importância do trabalho imaterial na valorização do capital, no entanto, não deve levar ao equívoco de que o mesmo prescinda do trabalho material que funciona como o vetor do valor, sem o qual, o trabalho imaterial, não pode se concretizar.

${ }^{29}$ Esse posicionamento se dá na análise das unidades industriais separadamente e não dentro do sistema capitalista como um todo, pois, dentro do novo padrão de organização do trabalho e de valorização do capital, os trabalhadores formais e informais são duas faces indissociáveis de uma mesma realidade. Para aprofundamento do tema ver a obra de Malaguti (2000).

${ }^{30}$ Nesta análise é preciso cuidado para não confundir o trabalho imaterial com o produto por ele fabricado.

${ }^{31} \mathrm{Na}$ fase atual do capitalismo a qualificação objetiva tampouco parece ser suficiente para inserção no mercado laboral em razão da excessiva contração da utilização de trabalho vivo no processo de 
por realizarem um trabalho totalmente desqualificado ( $v . g$., chapeiros, repositores, estoquistas, passeadores de cachorro, varredores de rua etc.). A situação beira o paroxismo: de um lado o capital necessita, cada vez mais, do conhecimento em seu processo de valorização; de outro, o movimento impulsiona a expansão acelerada de setores desqualificados de mão de obra.

Ocorre que os serviços não irão se reproduzir indefinidamente e o campo de inserção social que hoje se expande, para a maior parte da parcela populacional, é o de trabalhos precários, o que nega o potencial de libertação da tecnologia e produz graves fraturas no tecido social.

Assim sendo, poder-se-ia afirmar que está em curso uma mudança paradigmática da integração social, na qual, na medida em cada vez mais a integração social não mais é decorrente do mercado de trabalho, impor-se-ia a necessidade de se pensar novas formas de solidariedade social, novas formas de integração e de manutenção do corpo social. (Alvim e Fragale Filho, 2000, p. 160)

Se o trabalho assalariado detinha, no Estado Social, um papel de integração ao permitir que o salário funcionasse como mecanismo de distribuição de rendas, hoje já não mais é capaz de cumprir esse papel pelo estágio avançado do capitalismo. O problema, portanto, que se coloca não é tão só de produção, mas também de distribuição da riqueza social produzida, pois como poderá o sistema se estruturar sem a necessária circulação?

Então, nos parece necessário resgatar a centralidade do trabalho no processo de civilização dentro da sociedade capitalista e repensar o Estado e suas formas de estruturação na sociedade do século XXI. Contudo, velhas fórmulas são incapazes de responder a novos problemas, sendo necessário mudar a direção do pensamento. Neste sentido é que Gorz (1997) identifica a impossibilidade de se restabelecer a ideia de pleno emprego ${ }^{32}$ e a insustentabilidade da forma de cresci-

produção. Krugman (2001) em recente editorial do The New York Times aponta que a qualificação profissional e educação não garantem a inserção no mercado de trabalho e assevera que "[...] a ideia de que a tecnologia moderna elimina apenas os empregos para trabalhadores não qualificados, e de que os profissionais de alta qualificação são os nítidos vencedores, pode prevalecer nas discussões populares, mas a verdade é que tal ideia está superada há décadas. O fato é que desde mais ou menos 1990 o mercado de trabalho dos EUA caracteriza-se não por um aumento generalizado da demanda por qualificações, mas sim por um esvaziamento de uma "zona intermediária" [...] — ou seja, aquele tipo de trabalho que sustenta uma classe média robusta tem ficado para trás. E esse buraco no campo intermediário do mercado de trabalho tem aumentado continuamente [...]".

\footnotetext{
${ }^{32}$ Pensando nas críticas, é preciso marcar que Gorz (1980, 1997, 2003), em suas obras, não defende a perda de centralidade do trabalho em seu sentido ontológico. Ao contrário, defende a necessidade de que apenas o trabalho assalariado, e tão só esse, perca a centralidade na consciência da sociedade atual para que um novo sentir brote e possa recuperar o verdadeiro sentido do trabalho. Argumenta que a contínua defesa de algo já morto - a ideia do pleno emprego - prolonga artificialmente a situação atual, condutora de um crescimento que não questiona a sua finalidade, e, principalmente, impede que se pense sobre as inúmeras outras possibilidades existentes de nos fazermos sociedade.
} 
mento econômico capitalista evidenciado nos claros sinais de esgotamento dos recursos naturais.

O fato é que num mundo de integração socioeconômica crescente os problemas já não mais se aderem a imposições unilaterais, sendo preciso um pensar complexo ${ }^{33}$ capaz de reorganizar a esfera pública, em processos conjuntos de descentralização e de centralização, para além da dimensão espacial de Estados isolados. Isso, por sua vez, exige que o direito funcione como estrutura de coordenação entre ordens jurídicas estatais, transnacionais, internacionais e supranacionais.

No que tange à proteção social faz-se necessário pensar políticas públicas de proteção social amplificada, que devem ter sua legitimidade fundada na (re)interpretação da produção de riqueza, que tem sido velada, entre outros fatores, pelo distanciamento provocado pelas relações de produção e pelo ritmo frenético das finanças. Para isso deve-se estabelecer um projeto político que discuta o lugar do desenvolvimento tecnológico, assim como a redistribuição do tempo de trabalho e de seus rendimentos.

A economia clássica já consolidou a ideia de que o trabalho humano é o substrato do valor produzido na sociedade; noção que ganha especial relevo na fase do capitalismo do conhecimento, em que a riqueza está centrada nos saberes de socialização, pertencentes a todos que fazem a sociedade. De modo que devemos nos atentar ao modo de vida a que estão sendo submetidos os indivíduos, pois a modelagem de suas personalidades não constitui uma questão metafísica, mas empírica, e é resultante da natureza do homem e do efeito que certas condições exercem sobre ele (Fromm, 1941).

É preciso, portanto, ter claro: os sistemas de proteção social são garantias das condições mínimas de existência, que formatam um elemento psicológico que molda e compromete o próprio desenvolvimento dos indivíduos e permitem que nos façamos sociedade (Castel, 2005). A supressão dessas redes de proteção social ou sua diminuição não contribui ao nosso processo civilizacional, pois ao pôr em xeque estes mecanismos se produz uma fratura social em que indivíduo atomizado, sem amparo em seu entorno, modifica os sentidos de estar junto.

A realidade é fruto do desenvolvimento humano que

[...] parece ser um produto da interação entre duas premências, a premência no sentido de felicidade, que geralmente chamamos de "egoísta", e a premência no sentido da união com os outros da comunidade, que chamamos de "altruísta". [....] assim o indivíduo humano participa do curso do desenvolvimento da humanidade, ao mesmo tempo que persegue seu próprio caminho de vida. (Freud, 1930, p. 105)

\footnotetext{
${ }^{33}$ Morin (1982) explica que o pensamento complexo não é o da completude do conhecimento, mas o da sua incompletude. É, pois o pensamento que tenta afastar a simplificação mutilante por intermédio das articulações.
} 
Logo, estabelecer uma lógica mais sistêmica de proteção social pode permitir um maior desenvolvimento dos homens e de circulação de riquezas. Isso, contudo, só será possível se Estados diferentes se congregarem para discutir novos mecanismos de partilha do tempo de trabalho socialmente necessário de toda a riqueza social produzida e, inclusive, discutir o próprio sentido do que hoje se entende por trabalho. Tais propósitos “[...] no pudieron realizarse plenamente en ninguno de los períodos anteriores de la historia moderna; debieron permanecer en gran parte como fines ideológicos, pues faltaba la base material para el desarrollo de un genuino individualismo" (Fromm, 1941, p. 391). Agora, não mais!

\section{CONSIDERAÇÕES FINAIS}

A sociedade de especialistas, sob o véu da crença tradicional do caráter puramente racional do ato de pensar, tem construído esquemas e fórmulas acerca do projeto de vida, bem como do significado dos sujeitos. Padrões esses que fragmentam, desmembram, desarticulam o pensamento e, principalmente, obscurecem o processo dinâmico de construção social. Um olhar, no entanto, que fuja às alternativas redutoras - inclusive de modelos de Estado — pode nos permitir jogar luzes sobre o próprio processo civilizacional.

Os estímulos externos moldam a estrutura do caráter comum da maioria das pessoas no processo social. De modo que é no contexto histórico-social - material concreto - que o homem internaliza as necessidades externas para, então, conduzir a energia humana até as tarefas requeridas pelo sistema socioeconômico.

Ainda num movimento dúplice a realidade também constrói o não aparente — afetos, desejos e medos — que dinamicamente constrói a própria realidade. Trata-se de um movimento sutil que, por vezes, passa despercebido; sobretudo na fase atual, em que as pessoas, imersas num ritmo frenético e em padrões idealizados sobre o viver, vêm perdendo a relação consigo e com o mundo sem desenvolver a consciência sobre o processo que constroem e no qual estão inseridas.

Dá-se que, neste momento do capitalismo, há um deslocamento do valor para os processos de conhecimento centrados nos saberes comuns, em que os indivíduos, mais que em qualquer outra época, são o fator de valorização do capital. Noção esta que precisa ser evidenciada (já que obscurecida pelo distanciamento dos processos produtivos e pela aceleração do movimento das finanças) a fim de legitimar o estabelecimento de redes de proteção social amplificadas.

Essa construção mais sistêmica (que ultrapasse a configuração de um Estado isolado) de mecanismos de proteção social pode permitir o reencontro do homem com a pulsão da vida ao fazer possível estabelecer uma conectividade com o trabalho autônomo ou com o questionamento criativo, elementos fundamentais da natureza humana. Consequentemente pode liberar o homem de suas amarras e fomentar a riqueza das inovações pelas possibilidades do devir.

É preciso ter claro que a função das instituições é a de estabelecer políticas que 
respondam às necessidades presentes e prefigurem as possibilidades futuras, pois nada nasce ou fenece a um só golpe.

\section{REFERÊNCIAS BIBLIOGRÁFICAS}

ALVIM, Joaquim Leonel de Rezende \& FRAGALE FILHO, Roberto (2000) Justiça do trabalho: um paradigma em crise?" In ALVIM, Joaquim Leonel; FRAGALE FILHO, Roberto e JEAMMAUD, Antoine. Trabalho e Cidadania e Magistratura. Rio de Janeiro: Trabalhistas.

CASTEL, Robert (2005) A Insegurança Social: O que é ser Protegido? Petrópolis: Vozes, 2005.

DEBORD, Guy (1967 [2005]). A Sociedade do Espetáculo: Comentários sobre a Sociedade do Espetáculo. Rio de Janeiro: Contraponto.

DEPRESSÃO será doença mais grave em 2020. Boletim eletrônico da AAFIT-MG. 9 dez. 2009. Disponível em: <http://aafitmg.org.br/pages/noticias.php?id=414>. Acesso em: 16 jan. 2010.

ELIAS, Norbert (1990 [1994]) A Sociedade dos Indivíduos. Rio de Janeiro: Jorge Zahar Editor.

FILGUEIRAS, Fernando (2007) "Cohesión, riesgo y arquitectura de protección social en América Latina”. In Séries Políticas Sociales No 135. Santiago de Chile: Cepal, pp. 7-56.

FREUD, Sigmund. (1930 [1997]) O Mal-Estar na Civilização. Rio de Janeiro: Imago.

FROMM, Erich (1941, [1961] El Miedo a La Libertad. Trad. Gino Germani. Buenos Aires: Editorial Paidos.

GORZ, André (2003, [2005]). O Imaterial: Conhecimento, Valor e Capital. São Paulo: Annablume. . (1997, [2004]) Misérias do Presente, Riqueza do Possível. São Paulo: Annablume. .(1980, [1982]) Adeus ao Proletariado: Para além do Socialismo. Rio de Janeiro: Forense. . (2005) A crise e o êxodo da sociedade salarial.” Caderno Ideias. São Leopoldo. Ano 3, n. 31, pp. $1-16$.

HASSENTEUFEL, Patrick (1996) "L'État-Providence ou les metamorfoses de la citoyenneté". Revue L'Année Sociologique. Paris: PUF, Vol. 46/96, pp. 127-151.

KOSIK. Karel (1963, [1986]) Dialética do Concreto. 4. ed. RJ: Editora Paz e Terra.

KRUGMAN, Paul (2001) “Qualificação profissional e educação não garantem o futuro". The New York Times. 8 março 2001. Disponível em: <http://noticias.uol.com.br/blogs-colunas/colunas-do-new-york-times/paul-krugman/2011/03/08/qualificacoes>. Acesso em: 10 mar. 2011.

MALAGUTI, Manoel Luiz (2000, [2001]) Crítica à Razão Informal: A Imaterialidade do Salariado. São Paulo: Boitempo.

MANDEL, Ernest (1978) Iniciação à Teoria Econômica Marxista. 4. ed. Lisboa: Antídoto.

MORIN, Edgar (1996, "A noção de sujeito. In SCHINITMAN, Dora Fried. Novos Paradigmas: Cultura e Subjetividade. Porto Alegre: Artes Médicas, pp. 45-56. (1982, [1990]) Ciência com Consciência. São Paulo: Bertrand Brasil.

POCHMANN, Márcio (2004) Proteção Social na periferia do Capitalismo: considerações sobre o Brasil. Disponível em: <http://www.scielo.br/pdf/spp/v18n2/a02v18n2.pdf >. Acesso em: 12 dez. 2009. 